\section{Necrotic, ulcerative bronchitis, the presenting feature of lymphoproliferative disease following heart-lung transplantation}

\author{
Jim J Egan, Philip S Hasleton, \\ Nizar Yonan, Ali N Rahman, \\ Abdul K Deiraniya, Kevin B Carroll, \\ Ashley A Woodcock
}

\begin{abstract}
Following heart-lung transplantation two of 21 patients who survived more than 100 days developed post-transplant lymphoproliferative disease. Both presented with localised ulcerative bronchitis documented at flexible bronchoscopy four months after transplantation. Histological examination showed necrosis with acute inflammation and ulceration. Case 2 demonstrated lymphoproliferative disease from biopsies subsequently taken at rigid bronchoscopy. Case 1 later developed lung nodules and a monoclonal high grade $B$ cell non-Hodgkin's lymphoma was confirmed by an open lung biopsy. The bronchoscopic features described should alert clinicians to post-transplant lymphoproliferative disease as an underlying diagnosis and suggest that bronchus associated lymphoid tissue is the initial site for clonal proliferation in the disease. (Thorax 1995;50:205-207)
\end{abstract}

Keywords: ulcerative bronchitis, lymphoproliferative disease, heart-lung transplantation.

Immunosuppression and Epstein-Barr virus (EBV) have been linked to the development of post-transplant lymphoproliferative disease. ${ }^{1}$ It is thought to arise from abnormal $\mathrm{B}$ cell proliferation prompted by EBV infection and unchecked because of selective $T$ cell suppression by cyclosporin. ${ }^{2}$ The early diagnosis of posttransplant lymphoproliferative disease is important as the prompt institution of treatment may arrest the evolution of a simple EBV induced polyclonal $\mathrm{B}$ cell proliferation to a monoclonal B cell lymphoma. ${ }^{3}$
We report two heart-lung transplant recipients with a normal chest radiograph in whom the presence of an ulcerative bronchitis observed at fibreoptic bronchoscopy was an early clinical marker for post-transplant lymphoproliferative disease.

\section{Case 1}

A 45 year old woman underwent heart-lung transplantation for emphysema due to $\alpha_{1}$-antitrypsin deficiency. She received induction immunosuppression of methylprednisolone, $1 \mathrm{~g}$, azathioprine, $4 \mathrm{mg} / \mathrm{kg}$ before the transplant, and rabbit antithymocyte globulin, $1 \mathrm{mg} / \mathrm{kg}$ daily for three days, followed by maintenance immunosuppression of cyclosporin, oral prednisolone, and azathioprine. Four months after transplantation at the time of fibreoptic bronchoscopy and transbronchial biopsy an ulcerative bronchitis was observed. Histological examination of the bronchial biopsies demonstrated necrosis with an inflammatory infiltrate and ulceration. The transbronchial biopsy showed an interstitial pneumonitis which was considered to be due to cytomegalovirus. At follow up fibreoptic bronchoscopy Pseudomonas aeruginosa (three weeks later) and Aspergillus fumigatus (nine weeks) were cultured from the right lower lobe bronchial aspirate but, in spite of treatment with oral itraconazole, intravenous liposomal amphotericin, and nebulised amphotericin, the ulcerative bronchitis did not change. Following the demonstration of radiographic intrapulmonary nodules on thoracic computed tomographic scanning an open lung biopsy was performed three months after the initial observation of ulcerative bronchitis. This confirmed the presence of a monoclonal high grade B cell non-Hodgkin's lymphoma. There were no other extrathoracic features of non-Hodgkin's lymphoma such as lymphadenopathy, hepatosplenomegaly, bone marrow involvement, or a monoclonal paraproteinaemia, except an elevated lactate dehydrogenase level of $747 \mathrm{IU} / 1$ (normal range 200-600). In situ hybridisation was positive for EBV messenger RNA [small polyadenylated viral RNA, a marker of latent EBV infection] ${ }^{4}$ Intravenous acyclovir and reduced immunosuppression was initiated although there was no evidence of reactivation of EBV by IgG capsid serology (table). In the absence of a therapeutic response she then received combination chemotherapy with vincristine, adriamycin, prednisolone, etoposide, cyclophosphamide, bleomycin (VAPEC-B) and oral acyclovir. The patient died from respiratory failure six months after the documentation of the ulcerative bronchitis as a result of progressive lymphoma and invasive aspergillus disease. Post mortem histological examination demonstrated multiple areas of 
Donor and recipient Epstein-Barr virus serological data

\begin{tabular}{llll}
\hline Days after transplant & EBNA & VCA IgG & VCA IgM \\
\hline Case $1^{*}:$ & Positive & 320 & Negative \\
-2 & Positive & 160 & Negative \\
25 & Positive & 320 & Negative \\
122 & Positive & 80 & Negative \\
289 & & & Negative \\
Case $2+:$ & Positive & 80 & \\
-2 & Positive & 40 & Negative \\
19 & Positive & 40 & Negative \\
33 & Positive & 160 & Negative \\
73 & Positive & 160 & Negative \\
115 & - & 160 & Negative \\
161 & & Negtive
\end{tabular}

EBNA = Epstein-Barr nuclear antigen; VCA = viral capsid antigen. * Donor VCA IgG positive. + Donor VCA IgG negative.

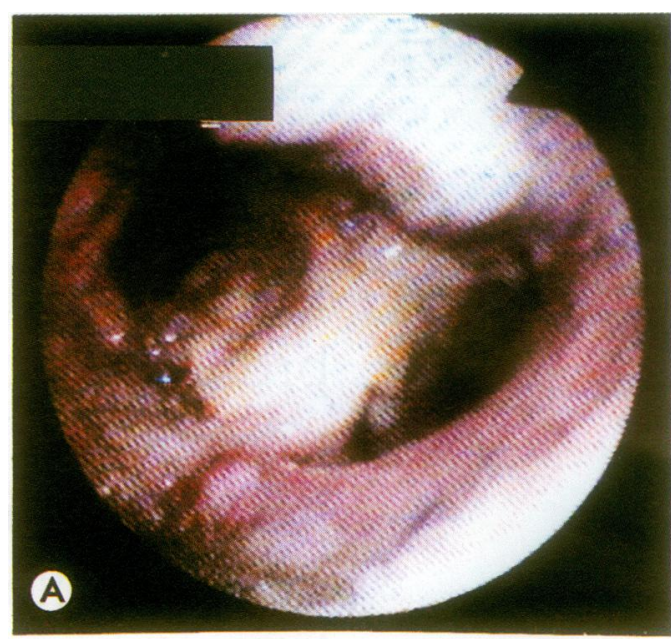

infiltration by high grade non-Hodgkin's lymphoma which were largely necrotic. Tumour cells were seen invading bronchi, blood vessels, and air spaces. The mediastinal nodes also showed necrotic lymphoma but no tumour was found in extrathoracic sites. Invasive aspergillosis was also present in the lung with infarctlike areas of necrosis and sloughing of bronchial epithelium.

\section{Case 2}

A 31 year old woman underwent heart-lung transplantation for primary pulmonary hypertension. She received induction and maintenance immunosuppression as detailed in case 1. Four months after transplantation, at the time of fibreoptic bronchoscopy and transbronchial biopsy, an ulcerative bronchitis was observed. The transbronchial biopsy showed no rejection but, in the presence of epithelial squamous cells and bile pigment, aspiration was considered. This ulcerative bronchitis progressed over three weeks to involve the carina and entire left main bronchus resulting in stridor (figure). Thoracic computed tomographic scanning demonstrated a mediastinal mass surrounding the left main bronchus. Further biopsies taken during rigid bronchoscopy demonstrated necrotic tissue with lymphoid tumour cells which were angiocentric and showed angioinvasion consistent with lymphoproliferative disease. Insufficient histological material was available for phenotyping of the disease. There was no evidence of reactivation of EBV using IgG capsid antigen serology (table) and there were no other systemic signs of post-transplant lymphoproliferative disease apart from an elevated lactate dehydrogenase level of 945 IU/I (normal range 200-600). The available tissue was unsuitable for the detection of EBV messenger RNA using in situ hybridisation. No response was obtained with intravenous acyclovir and reduced immunosuppression. The patient then received VAPEC-B with complete remission of the lymphoma and she is alive 10 months after the diagnosis of post-transplant lymphoproliferative disease.

\section{Discussion}

Heart-lung transplant recipients are par-

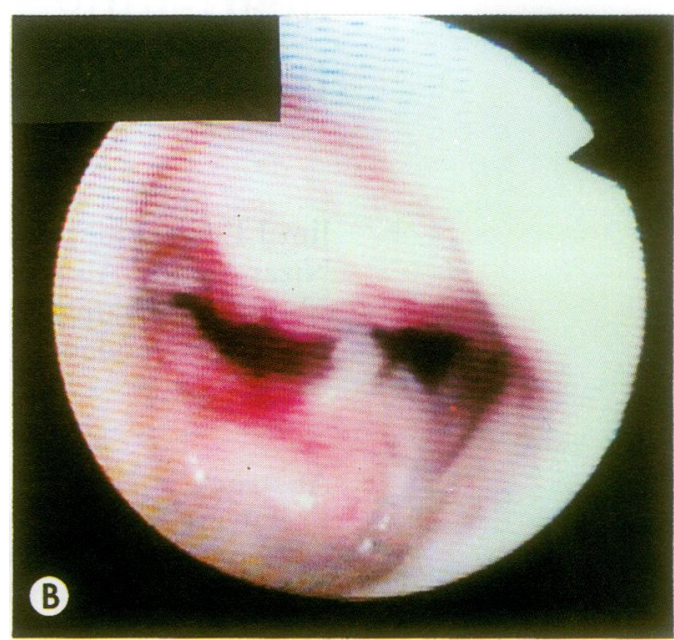

(A) Ulcerative bronchitis involving the carina. (B) The appearance of the left main bronchus at bronchoscopy demonstrating bronchitis and distal obstruction.

ticularly prone to developing post-transplant lymphoproliferative disease within the lung graft with a quoted incidence in the region of $8 \% .^{5}$ Cell necrosis and necrotising vasculitis with destruction of the walls of small bronchi are a consistent histological feature of posttransplant lymphoproliferative disease in heartlung transplant recipients. $^{6}$ Yousem et al postulated that bronchus associated lymphoid tissue (BALT) may provide an environment for uncontrolled clonal proliferation of B lymphocytes resulting in the development of posttransplant lymphoproliferative disease in heartlung transplant recipients. ${ }^{6}$ Our observations conform clinically with such a hypothesis as the consistent features in both these cases were those of necrotic bronchial changes. The presence of BALT in adults remains controversial, but recent postmortem findings suggest that large airway BALT does exist in the presence of antigenic stimuli. ${ }^{7}$

Like other published series of post-transplant lymphoproliferative disease in heart-lung transplant recipients a common characteristic in our cases was the early presentation within the graft (four months) following transplantation. The reason for this remains unclear but, as prospective donor/recipient HLA matching does not occur, it is possible that chronic antigenic stimulation due to rejection in conjunction with 
latent EBV genome in the graft BALT results in the post-transplant lymphoproliferative disease evolving rapidly. The chronic antigenic stimulation which occurs with repeated malarial infections is considered to be an important adjunct to EBV in the development of Burkitt's lymphoma. ${ }^{8}$

Bronchial changes have been documented in the presence of pathogenic organisms such as Aspergillus. ${ }^{9}$ In case 1 the presence of Pseudomonas aeruginosa annd Aspergillus resulted in therapeutic trials which delayed the diagnosis of post-transplant lymphoproliferative disease.

In the clinical/pathological spectrum of posttransplant lymphoproliferative disease a benign lymphoid proliferative response to EBV may respond to a reduction in immunotherapy and antiviral agents. Early intervention in posttransplant lymphoproliferative disease may therefore prevent the progression of the disease since ganciclovir has been shown to inhibit the development of B cell lymphoma in an immunocompromised mouse model. ${ }^{10}$

Ulcerative bronchitis in a heart-lung transplant recipient may be the first sign of posttransplant lymphoproliferative disease, and suggests that BALT in the grafted lung is an important site for the initiation of clonal B cell proliferation in post-transplant lymphoproliferative disease.
We acknowledge Dr Andrew Turner, Consultant Virologist, Public Health Laboratory, Withington Hospital, Manchester for his help in assessing the EBV serology. We also wish to for his help in assessing the EBV serology. We also wish to
thank Dr J Alero Thomas, Senior Clinical Lecturer of the thank Dr J Alero Thomas, Senior Clinical Lecturer of the pleting the in situ hybridisation studies.

1 Nagington J, Gray J. Cyclosporin A immunosuppression, Epstein-Barr antibody and lymphoma. Lancet 1980;i:536-7.

2 Thomas JA, Crawford DH. B-cell lymphoma in organ transplant recipients. Semin Thorac Cardiovasc Surg 1990;2: 221-32.

3 Nalesnik MA, Jaffe R, Starzl T, Demetris AJ, Porter K, Burnham JA, et al. The pathology of posttransplant lymphoproliferative disorders occurring in the setting of cyclooproliferative disorders occurring in the setting of cyclo-
sporine A-prednisolone immunosuppression. Am $\mathcal{F}$ Pathol

4 Arrand JR, Rymo L. Characterisation of the major EpsteinBarr virus-specific RNA in Burkitt's lymphoma-derived cells. $\mathcal{F}$ Virol 1982;41:376-89.

5 Armitage JM, Kormos RL, Stuart S, Fricker FJ, Griffith BP, Nalenik M, et al. Posttransplant lymphoproliferative disease in thoracic organ transplant patients: ten years of cyclosporine-based immunosuppression. 7 Heart Lung Transplant 1991;10:877-87.

6 Yousem SA, Randhawa P, Locker J, Paradis IL, Dauber JA, Griffith BP, et al. Posttransplant lymphoproliferative disorders in the heart-lung transplant recipients: primary disorders in the heart-lung transplant recipients: primary
presentation in the allograft. Hum Pathol 1989;20:361-9.

presentation in the allograft. Hum Pathol 1989;20:361-9. EH. Bronchus associated lymphoid tissue (BALT) in human lung: its distribution in smokers and non-smokers. Thorax 1993;48:1130-4.

8 Editorial. Epstein-Barr virus and AIDS-associated lymphomas. Lancet 1991;338:979-81.

9 Kramer MR, Denning DW, Marshall SE, Ross DJ, Berry $\mathrm{G}$, Lewiston NJ, et al. Ulcerative tracheobronchitis after lung transplantation. A new form of invasive aspergillosis. Am Rev Respir Dis 1991;144:553-6.

10 Boyle TJ, Tamurini M, Berend KR, Kizilbash AM, Borowitz MJ, Lyerly HK. Human B-cell lymphoma in severe combined immunodeficient mice after active infection with Epstein-Barr virus. Surgery 1992;112:378-86.
Department of Thoracic Medicine N Sheerin

N K Harrison

T J H Clark

Department of Lung Pathology

M N Sheppard

Department of

Radiology

D M Hansell

Department of Thoracic Surgery $M$ Yacoub

Royal Brompton National Heart and Lung Hospital, Sydney Street, London SW3 6NP, UK

Reprint requests to: Professor T J H Clark.

Received 26 August 1993 Returned to authors 21 October 1993 Revised version received 18 February 1994 Accepted for publication 22 February 1994
Obliterative bronchiolitis caused by multiple tumourlets and microcarcinoids successfully treated by single lung transplantation

\author{
N Sheerin, N K Harrison, \\ M N Sheppard, D M Hansell, \\ M Yacoub, T J H Clark
}

\begin{abstract}
Histological examination of a lung removed at transplantation revealed multiple peripheral tumourlets and microcarcinoids in close association with bronchioles causing an obliterative bronchiolitis. This was an unexpected
\end{abstract}

finding but explained the progressive airflow limitation which characterised the patient's clinical course.

(Thorax 1995;50:207-209)

Keywords: obliterative bronchiolitis, tumourlets, single lung transplantation.

Multiple tumourlets arising in the lung are usually regarded as benign although they can show malignant potential. ${ }^{1}$ They share a similar phenotype to carcinoid tumours, both showing neuroendocrine features but no cytological evidence of malignancy. ${ }^{2}$ Unlike true carcinoids they are rarely of clinical significance, although a recent report suggests that they may be associated with airways obstruction. ${ }^{3}$ We describe a patient in whom multiple pulmonary tumourlets and microcarcinoids occurred within the small airways resulting in a progressive obliterative bronchiolitis and severe airflow limitation. This was successfully treated by single lung transplantation.

Case report

A 42 year old white woman presented with a 10 year history of progressive airflow limitation. She had previously smoked a total of five packyears. Pulmonary function tests showed: forced expiratory volume in one second $\left(\mathrm{FEV}_{1}\right)(\%$ predicted) $840 \mathrm{ml}(28 \%)$, forced vital capacity (FVC) $3160 \mathrm{ml}$ (89\%), peak expiratory flow 